\title{
An Elementary Process in the Thermal Shrinkage of Cold-Drawn Polycarbonate
}

\author{
Masakatsu KochI, Tetsuo SASAKI, ${ }^{*}$ and Hirotaro KaMBE \\ Institute of Space and Aeronautical Science, University of Tokyo, \\ Komaba, Meguro-ku, Tokyo 153, Japan.
}

(Received June 23, 1977)

\begin{abstract}
An elementary process preceding glass transition was found in the measurement of the thermal shrinkage of cold-drawn polycarbonate (PC) film by a thermo-mechanical analyzer. An activation energy spectrum associated with the shrinkage of $7 \%$ cold-drawn PC was derived using Primak's method for processes distributed in activation energy. The spectrum showed two maxima centered at about 15 and $18 \mathrm{kcal} / \mathrm{mol}$, respectively. This was consistent with the result of dielectric measurements. In the latter, two additional relaxations due to the drawing effect were observed. These molecular relaxations indicate the existence of limited chain-backbone motions in the glassy state of cold-drawn PC. It was also shown that molecular packing is closely related to these relaxations.
\end{abstract}

KEY WORDS Polycarbonate / Thermal Shrinkage / TMA / Cold-

Drawing / Activation Energy Spectrum / Primak's Method / Limited

Chain-Backbone Motion / Molecular Packing /

The cold-drawing of polymers is not only important in processing technology, but also very interesting from the standpoint of molecular motions in the deformed polymer systems.

There have been a number of investigations on the molecular mechanism of cold-drawing and/or thermal shrinkage for polymer films. However, most processes of thermal shrinkage are discussed in the glass transition region. ${ }^{1-4}$ We showed in our previous papers ${ }^{5,6}$ the elementary processes for thermal shrinkage of the cold-drawn polypyromellitimide films in which some local chainbackbone motions occurred. The analysis was made for each molecular motion going on the assumption of a unique process with a single activation energy. It was found, however, that the activation energy obtained was not exactly constant. On the other hand, we have shown the validity of Primak's method in analyzing the derivative heating curve of cold-drawn polycarbonate which was obtained by a graphical differentiation. ${ }^{7}$ This method $^{8,9}$ based on processes distributed in activation energy is considered to give more realistic kinetics of processes in an amorphous solid.

* Present address: Hodogaya Chemical Co. Ltd., 6-2-60, Oji, Kita-ku, Tokyo 114, Japan.
Park and Uhlmann ${ }^{2}$ applied this method to the analysis of isothermal annealing of highly colddrawn polymers. Recently, Ikeda and Matsuda ${ }^{3}$ proposed including a correlation between activated processes in the fundamental equation of the Primak theory.

In this paper, we show an elementary process of thermal shrinkage of PC found by thermomechanical measurements. The kinetic data obtained at a constant rate of heating is analyzed by Primak's method, as in a previous paper. ${ }^{7}$

\section{EXPERIMENTAL}

Poly(bisphenol A carbonate) (PC) used in this research was supplied by Teijin Co. Ltd. Some samples were annealed in a vacuum furnace for $72 \mathrm{hr}$ at $110^{\circ} \mathrm{C}$. For drawing experiments, a sample sheet, $100-\mu$ thick, was cut to a specimen strip of $8 \times 60 \mathrm{~mm}$. The specimen film was drawn by a Toyo-Boldwin tensile testing machine with a head sheep of $1 / 3600 \mathrm{sec}^{-1}$ at room temperature. All the drawn films were relaxed at the final extension length for $30 \mathrm{~min}$ in the machine. The final extension of $7 \%$ was chosen to study the elementary process of thermal shrinkage in detail. Below this extension, PC film did not exhibit 
necking.

The thermal shrinkage of cold-drawn films was measured with a Rigaku Denki Thermomechanical Analyzer. The schematic diagram of this apparatus is described elesewhere. ${ }^{6}$ Derivative heating curves with respect to temperature were recorded by a derivative circuit. The applied load was kept constant at $2 \mathrm{~g}$.

Dielectric measurements were made with a Ando Denki TR-1B Transducer Bridge between $30 \mathrm{~Hz}$ and $30 \mathrm{kHz}$ at the heating rate of $1^{\circ} \mathrm{C} / \mathrm{min}$.

Density was determined with a $\mathrm{NaBr}-\mathrm{H}_{2} \mathrm{O}$ density gradient column to a precision of \pm 0.0003 $\mathrm{g} / \mathrm{cm}^{3}$. Samples reached a constant position in the cloumn within $2 \mathrm{hr}$.

\section{RESULTS}

The derivative heating curves of thermal shrinkage with the heating rate of $10^{\circ} \mathrm{C} / \mathrm{min}$ is shown in Figure 1 for 7 and 60-\% cold-drawn PC. The relative derivative shrinkage is plotted against temperature $T$. As seen in Figure 1, two peaks were observed for the annealed $7 \%$ cold-drawn PC film; a higher peak at about $35^{\circ} \mathrm{C}$ and a lower one at about $95^{\circ} \mathrm{C}$. The not-annealed $7-\%$ drawn sample showed a high peak at about $90^{\circ} \mathrm{C}$. For the annealed $60 \%$ cold-drawn PC film, two shoulders appeared below $120^{\circ} \mathrm{C}$, and plots of the derivative curve were divergent in the glass transition region of $\mathrm{PC}$ above $120^{\circ} \mathrm{C}$.

The dependence of the dielectric loss tangent, $\tan \delta$, on temperature is shown in Figure 2 for 3

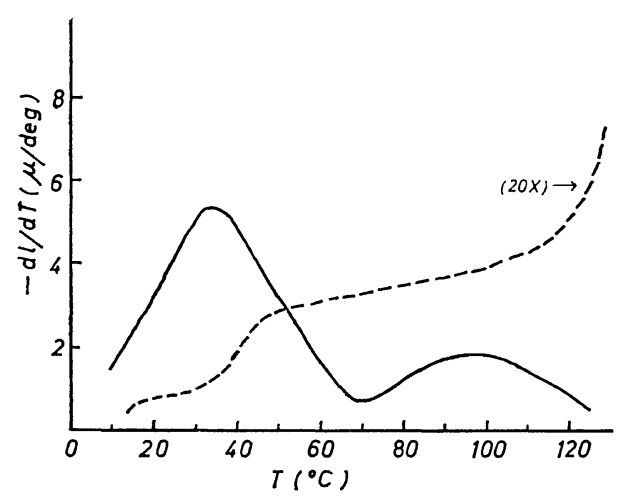

Figure 1. Derivative heating curves of thermal shrinkage with heating rate of $10^{\circ} \mathrm{C} / \mathrm{min}$ : annealed 7- $\%$ cold-drawn; ------, annealed $60-\%$ colddrawn.

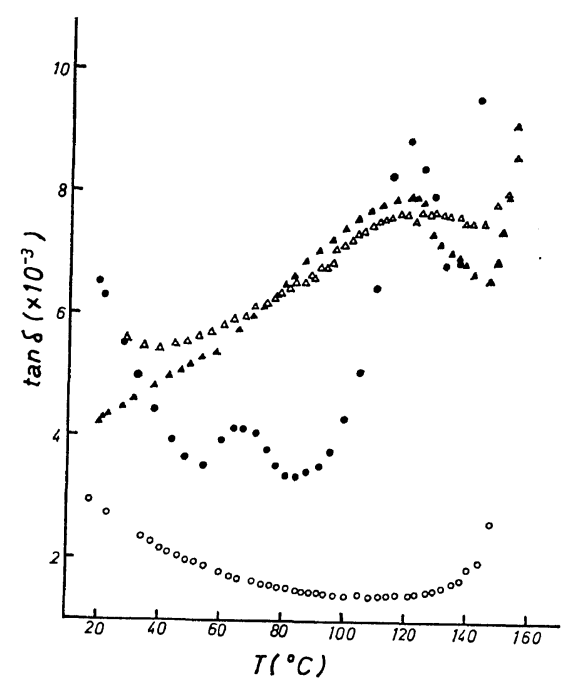

Figure 2. Dielectric loss tangent $(\tan \delta)$ at $3 \mathrm{kHz}$ : $\Delta$, not-annealed and undrawn; $\triangle$, not-annealed $7-\%$ drawn; 9 , annealed $7-\%$ drawn; $O$, annealed undrawn.

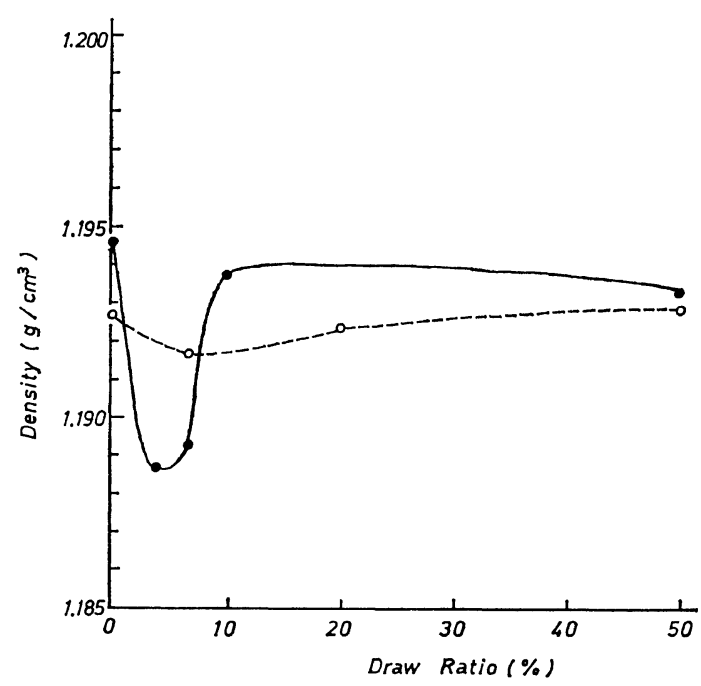

Figure 3. Density change on drawing: $\bullet$, annealed; O, not-annealed.

$\mathrm{kHz}$. Though not shown in the figure, the $\alpha$ peak corresponding to the glass transition of PC was observed at about $170^{\circ} \mathrm{C}$ in all samples. As is evident, the broad peak located in the interval from $60^{\circ}$ to $130^{\circ}$ for the sample as-received disappeared in the case of the annealed sample. In the annealed $7-\%$ drawn sample, two secondary dielectric dispersion peaks were observed at around $120^{\circ} \mathrm{C}$ and $65^{\circ} \mathrm{C}$ and in the present study, are re- 
ferred to as $\beta$ and $\beta^{\prime}$ losses, respectively. These losses were not so clearly observed as peaks at other frequency ranges. However, only one broad dispersion peak similar to that of the as-received sample was seen for the $7-\%$ drawn sample not annealed.

Figure 3 shows the density change on drawing for the as-received and annealed PC films. The density of the as-received film is seen to increase upon annealing. Further, the density of the annealed sample decreased once before necking and did not return to its initial value, even when drawn by $50 \%$. On the other hand, the density of the as-received film did not show any remarkable change by $50 \%$ drawing.

\section{DISCUSSION}

We have applied Primak's method to the thermomechanical data of Figure 1. The correlation effect is neglected in the present analysis, because molecular motions are not so extensive in an elementary process as in the glass transition region.

The principal equations for heating process are written as ${ }^{8}$

$$
\begin{aligned}
p(\bar{\varepsilon}) & =-\frac{\mathrm{d} l}{\mathrm{~d}(R T)} \cdot \frac{1}{(\xi / b)+1} \\
\bar{\varepsilon} & =(R T \xi) / b \\
\xi & =-a+-\ln (B c R T)
\end{aligned}
$$

Here, $p$ is the distribution function of activation energy, $\bar{\varepsilon}$ the characteristic energy at which the maximum rate of thermal shrinkage occurs, $l$ the sample length, $R$ the gas constant, $T$ the temperature, $B$ the frequency factor, $c$ the reciprocal heating rate, $a$ and $b$ constants, respectively. Equation 1 indicate that an activation energy spectrum $p(\bar{\varepsilon})$ is easily obtained from a derivative heating curve of TMA, $-\mathrm{d} l / \mathrm{d} T$.

Figure 4 shows the activation energy spectrum of the $7-\%$ cold-drawn PC calculated from the derivative curve in Figure 1, using eq 1 . The value of $B, 5 \times 10^{8} \mathrm{sec}^{-1}$, was determined experimentally. ${ }^{7}$ As seen from Figure 4, the spectrum shows a sharp peak at about $15 \mathrm{kcal} / \mathrm{mol}$ and a broad one at about $18 \mathrm{kcal} / \mathrm{mol}$. By comparing this spectrum with the dielectric behavior of the annealed $7-\%$ cold-drawn PC in Figure 2, we conclude that the smaller activation energy is ascribed to the $\beta^{\prime}$-loss and the larger one to the $\beta$ -

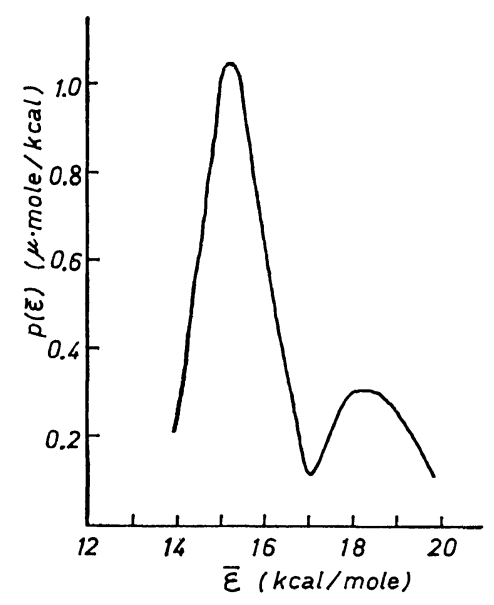

Figure 4. Activation energy spectrum for annealed $7-\%$ cold-drawn PC.

loss, respectively.

It is well known that an additional molecular relaxation appears for the highly-drawn PC. Krum and Müller ${ }^{10}$ observed broad dispersion peak at around $40^{\circ}-120^{\circ} \mathrm{C}$ in the dielectric measurement at $1 \mathrm{kHz}$. Lunn and Yannas ${ }^{11}$ found a limited chain-backbone motion by measuring the change of dichroism during isothermal annealing. For undrawn materials, secondary relaxations at around $50-100^{\circ} \mathrm{C}$ have been reported. ${ }^{12,13}$

Sacher ${ }^{14}$ found a new secondary loss at about $30^{\circ} \mathrm{C}$ in addition to the one at about $130^{\circ} \mathrm{C}$. He claimed that the latter may involve more chain segments than the former.

In the present study, a broad secondary loss peak was observed for the not-annealed PC, but two peaks appeared separately for the annealed drawn sample. Since they appear in the dielectric measurement and disappear simultaneously on annealing below $T_{\mathrm{g}}$, these two relaxations seem to be fairly coupled together. Locati and Tobo$1 s k y^{15}$ already found splitting of the broad $\gamma$-peak of $\mathrm{PC}$ at around $-60-120^{\circ} \mathrm{C}$ into two processes. Both of our peaks must surely originate from a main chain motion, since side group motions never cause thermal shrinkage. However, the activation energies are substantially less than the value of $100-115 \mathrm{kcal} / \mathrm{mol}^{10,16}$ reported for the glass transition (or $\alpha$ ) peak. Thus, the $\beta$ and $\beta^{\prime}$-peak may involve main chain motions like those in the $\alpha$-peak, although not so extensive. The shrinkage attributed to these relaxations is estimated to be 
within about $7 \%$.

Structural changes of PC caused by annealing at temperatures below $T_{\mathrm{g}}$ have been suggested by several authors. ${ }^{17-19}$ As to the change in density in Figure 3, the increase in density upon annealing and the decrease in density upon cold drawing indicate the formation and the destruction of some ordered region, respectively. By using the smallangle X-ray scattering, the effect of annealing and drawing on density, similar to that mentioned above, has been confirmed for aromatic polyimide and polyamideimide, and is attributed to the packing change. ${ }^{20}$ Consequently, the molecular motions deriving from $\beta$ and $\beta^{\prime}$-losses are raised in the amorphous region. Sacher ${ }^{14}$ also showed that the peak area of the two secondary losses observed by him increases noticeably with decreasing crystallinity.

From these considerations, it is concluded that the molecular motions involved in the $\beta$ and $\beta^{\prime}$ losses are the coupled, dielectrically active and limited chain-backbone motions encompassing few repeating units, and that these are liberated in the elementary thermal shrinkage process preceding the glass transition process.

\section{REFERENCES}

1. T. Ishinabe, K. Shinoda, H. Sugao, and K. Ishikawa, Kobunshi Kagaku (Chem. High Polymers, Japan), 29, 56 (1972).

2. J. Park and D. R. Uhlmann, J. Appl. Phys., 41, 2928 (1970).
3. S. Ikeda and K. Matsuda, J. Polym. Sci. (Phys.), 13, 1913 (1975).

4. T. Kato and H. Kambe, J. Appl. Polym. Sci., in press.

5. H. Kambe and T. Kato, J. Appl. Polym. Symp., No. 20, 365 (1973).

6. H. Kambe, T. Kato, and M. Kochi, J. Macromol. Sci. -Chem., A8, 157 (1974).

7. M. Kochi, T. Sasaki, M. Murakami, and H. Kambe, Rep. Prog. Polym. Phys. Jpn., 17, 307 (1974).

8. W. Primak, Phys. Rev., 100, 1677 (1955).

9. W. Primak, J. Appl. Phys., 31, 1524 (1960).

10. F. Krum and F. H. Müller, Kolloid $Z$., 164, 6 (1959).

11. A. C. Lunn and I. V. Yannas, J. Polym. Sci. (Phys.), 10, 2189 (1972).

12. T. Hara and S. Okamoto, Jpn. J. Appl. Phys., 3, 499 (1964).

13. P. H. Geil and K. Neki, J. Macromol. Sci.-Phys., B8, 295 (1973).

14. E. Sacher, J. Macromol. Sci.-Phys., B10, 319 (1974).

15. G. Locati and A. V. Tobolsky, Adv. Mol. Relax. Proc., 1, 375 (1970).

16. D. J. Matz, W. G. Guldemond, and S. L. Cooper, J. Polym. Sci., Polym. Phys. Ed., 10, 1917 (1972).

17. W. Frank, H. Goddar, and H. A. Stuart, J. Polym. Sci., Part B, 5, 711 (1967).

18. A. Siegmann and P. H. Geil, J. Macromol. Sci.Phys., B4, 239, 273 (1970).

19. D. G. LeGrand, J. Appl. Polym. Sci., 16, 1367 (1972).

20. S. Isoda, M. Kochi, and H. Kambe, Rep. Prog. Polym. Phys. Jpn., in press. 